\title{
Quantitative enzyme cytochemistry of leukaemic cells
}

\author{
J. STUART, LUCILLE BITENSKY, AND J. CHAYEN \\ From the Department of Haematology, the Children's Hospital, Birmingham, \\ and the Division of Cellular Biology, the Kennedy Institute of Rheumatology, London
}

SYNOPSIS A new technique for the quantitative estimation of glycolytic and respiratory enzyme activity in intact and unfixed bone marrow and peripheral blood cells is described. The method gives a two- to three-fold increase in demonstrable enzyme activity per cell compared with existing techniques using fixed marrow film preparations, and is particularly applicable to the study of relatively fragile cells such as the leukaemic lymphoblast.

The cytochemical demonstration of enzyme activity in individual bone marrow and peripheral blood white cells has been hampered by technical difficulties. When these cells are smeared on to glass slides, fixation of the cells is required to prevent their subsequent disruption when the slide is incubated in an appropriate working solution. Acetone at room temperature (Quaglino and Hayhoe, 1960) and ethanol at $-70^{\circ} \mathrm{C}$ (Stuart and Skowron, 1968) are relatively suitable fixatives for the demonstration of dehydrogenase activity in bone marrow cells but, in common with other fixatives, inevitably result in inhibition of a variable amount of enzyme activity, and their use, therefore, merely represents a compromise between adequate cell preservation and the avoidance of excessive enzyme inhibition.

In view of the recent interest in dehydrogenase activity in leukaemic cells (Hayhoe, Quaglino, and Doll, 1964) and the demonstration by homogenate studies of a deletion of the enzyme $a$-glycerophosphate dehydrogenase in mouse leukaemia (Sacktor and Dick, 1960), we have attempted to develop a method to allow the cytochemical study of enzyme activity in human marrow cells without the inhibiting effect of a fixative. The immature leukaemic blast cell is particularly vulnerable to cellular damage caused by the lateral shearing force involved in spreading a marrow or blood film and the technique was also designed to eliminate this step. The use of semi-quantitative scoring techniques to assess enzyme activity, as in the leucocyte alkaline phosphatase reaction, considerably limits the accuracy of these procedures and to overcome this disadvantage we have instead used a scanning and integrating microdensitometer (Deeley, 1955; Chayen and
Denby, 1968) which allows a more accurate and objective estimation of enzymatic reactions in individual cells.

\section{METHOD}

PRINCIPLE The soluble tetrazolium salt nitroblue tetrazolium is reduced to a coloured formazan which is deposited inside cells in proportion to dehydrogenase activity.

PROCEDURE Add one drop of bone marrow aspirate, containing EDTA (sequestrene) as anticoagulant, to $0.5 \mathrm{ml}$ of incubation solution containing appropriate substrate and coenzyme dissolved in $0.05 \mathrm{M}$ glycyl glycine buffer at a final $p \mathrm{H}$ of $7 \cdot 4$.

$$
\begin{aligned}
& \text { For lactate dehydrogenase } \\
& \text { Nitroblue tetrazolium ............ } 5 \mathrm{mg} \\
& \text { Calcium chloride }\left(\mathrm{CaCl}_{2} .2 \mathrm{H}_{2} \mathrm{O}\right) \ldots \ldots \ldots 65 \mathrm{mg} \\
& \text { Collagen polypeptide }{ }^{1} \ldots \ldots \ldots \ldots \ldots \ldots .2 \mathrm{mg} \\
& \text { Nicotinamide adenine dinucleotide (NAD) } 5 \mathrm{mg} \\
& \text { Sodium lactate solution }(72 \% \mathrm{w} / \mathrm{w}) \ldots \ldots .0 .02 \mathrm{ml} \\
& \text { Glycyl glycine buffer ............. } 5 \mathrm{ml}
\end{aligned}
$$

2 Incubate for 60 minutes at $37^{\circ} \mathrm{C}$ in an atmosphere of nitrogen. Then centrifuge for two minutes at $3,000 \mathrm{rpm}$, remove the supernatant and resuspend the cells in $1 \mathrm{ml}$ of $5 \%$ glucose containing $2 \%$ Tween 80 . Transfer the cells to glass slides by centrifugation for five minutes at $1,000 \mathrm{rpm}$ in a Shandon cytocentrifuge.

3 Air dry, and fix for 10 minutes in a $40 \%$ formalin solution. Counterstain for 10 minutes with $2 \%$ aqueous methyl green.

The amount of formazan present in individual cells was assessed by means of a Barr and Stroud scanning and integrating microdensitometer (type GN 2), using a $\times 100$ oil-immersion objective. 


\section{RESULTS}

The amount of formazan deposited in individual cells by this technique was compared with that obtained in marrow films spread in the conventional way, fixed for 30 seconds in acetone at $20^{\circ} \mathrm{C}$, and subsequently immersed in the appropriate incubation solution. Compared with the fixed smear technique, the cell suspension method showed a consistent increase in the amount of formazan produced, the extent of the increase depending on the enzyme under study, the cell type, and the duration of incubation. The leukaemic lymphoblast showed an approximately two-fold increase after incubation for 80 minutes (Figs. 1 and 2) for both lactate and glucose-6-phosphate dehydrogenases, while the small lymphocyte showed a slightly smaller increase. Secondary deposits of neuroblastoma cells in bone marrow, which have a higher activity of both enzymes than cells of the lymphoid series, showed the greatest increase of the cells studied (Fig. 3). In terms of the actual amount of stain (formazan) per cell after 40 minutes' incubation, those neuroblastoma cells treated by the new technique contained 85 units in comparison with 25 units in cells tested as a fixed smear. The response of the enzyme to exogenous substrate (test minus control) was $\mathbf{4 0}$ and 10 units respectively. Normal marrow cells showed a variable increase which was dependent on their intrinsic dehydrogenase activity.

\section{DISCUSSION}

A previous attempt to complete the cytochemical reaction in cells suspended in a working solution before their transfer to slides (De Souza and Kothare, 1959) has not been widely adopted because

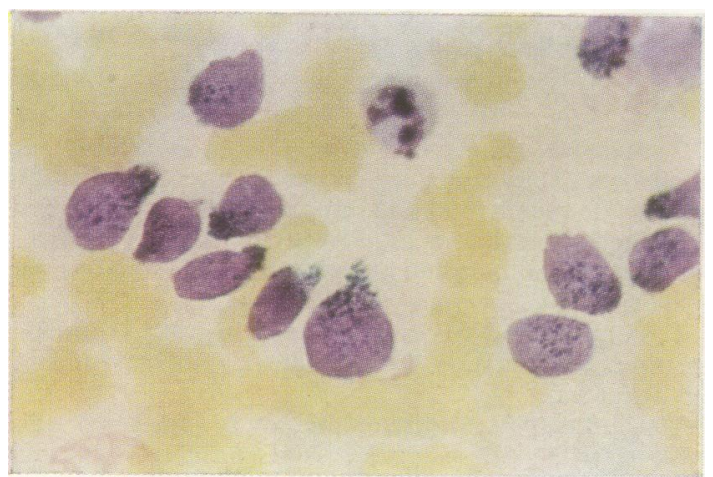

FIG. 1. Lactate dehydrogenase in acetone-fixed marrow film counterstained with Carazzi's haematoxylin.

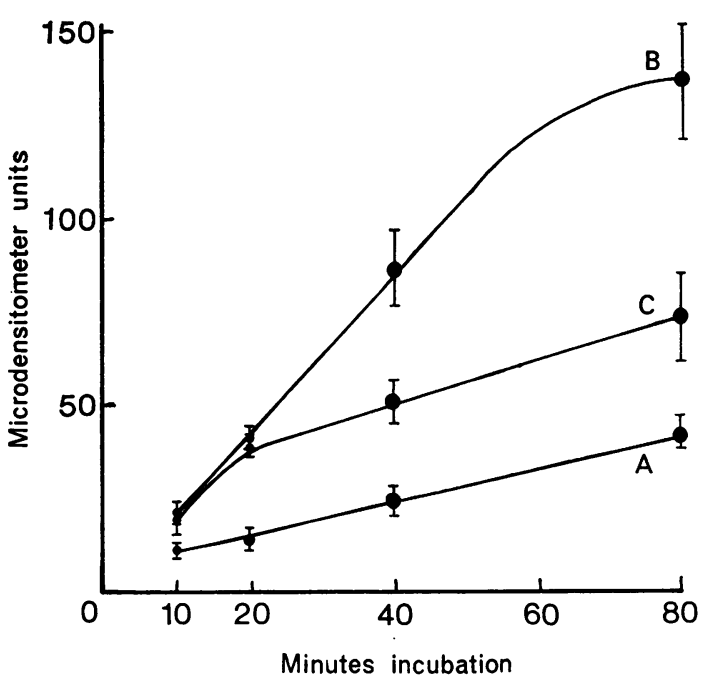

FIG. 3. Time-activity curves comparing the production of formazan in fixed marrow smears (A) with that obtained $\Phi$ with the cell suspension technique in the presence (exogenous $\overrightarrow{-}$ activity) (B) and absence (endogenous activity) (C) of $\mathscr{\circ}$ substrate in the incubation mixture. The points shown 6 represent the mean scores, in arbitrary microdensitometer $\square$ units, for 50 cells \pm 1 standard deviation.

considerable damage to the cells tends to occur $\stackrel{\square}{\square}$ during incubation. The use of additives such as $\overrightarrow{\vec{A}}$ polyvinyl alcohol, which increase the density of the 3 incubation solution and also decrease cell damage $\overrightarrow{ }$ during incubation, was found to be of benefit in a previous study of fixed marrow films (Stuart and Skowron, 1968) and has now been found to increase? the preservation of individual cells suspended freely

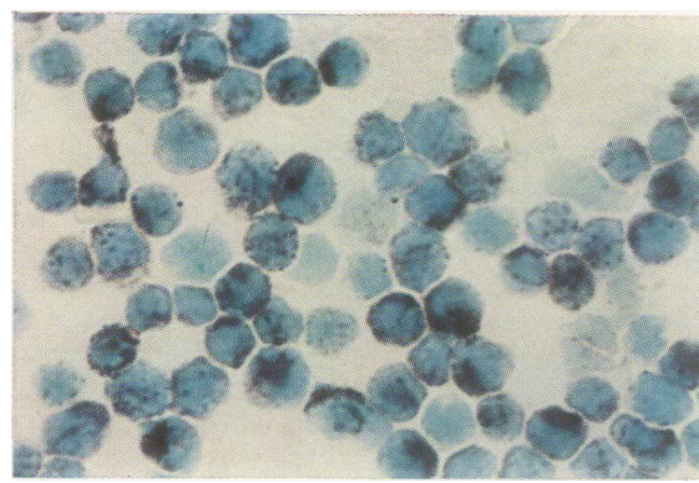

FIG. 2. Cell suspension: cytocentrifuge preparation of the same specimen counterstained with methyl green.

FIGS. 1-2. Dehydrogenase activity in leukaemic lymphoblasts. 
in an incubation solution. The use of a $40 \%$ concentration of a polypeptide (molecular weight approximately 15,000 ) derived from collagen by enzymatic degradation is superior to polyvinyl alcohol for the latter purpose, and when the enzymatic reaction is complete the polypeptide medium can be removed by washing the cells in $5 \%$ glucose containing $2 \%$ Tween 80 .

While suspended freely in this incubation mixture the marrow cells retain their normal globular shape and in order to convert them into a flattened form on glass slides, as is necessary for accurate haematological characterization, the cytocentrifuge was used. This allows the cells to be flattened by centrifugal force directly on to glass slides, so avoiding a disruptive lateral shearing effect. The resulting cells are slightly smaller than on conventional marrow films but an accurate morphological classification can be made within the limits of the counterstain and the intensity of the black formazan deposit. In these experiments the cell nuclei were counterstained with methyl green and microdensitometer readings were taken in green light (wavelength $550 \lambda$ ) which was absorbed almost maximally by the formazan but not appreciably by the methyl green. Thus variations in nuclear size and mass had a minimal effect on individual cell readings compared with the amount of formazan present. Morphological recognition of individual cells was aided by prior viewing in white or red light.

In developing this technique attention was concentrated on the enzymes lactate dehydrogenase and glucose-6-phosphate dehydrogenase since these are soluble, cytoplasmic enzymes which are readily lost from the cell when the cell membrane is damaged. Previous studies of these enzymes in fixed, smeared marrow films revealed that the formazan deposit in the cytoplasm of individual cells was predominantly granular in nature (see Fig. 1) with a minimal diffuse component. With the cell suspension technique the amount of formazan in each cell is considerably increased and the increase is predominantly in the diffuse component (see Fig. 2). Since these are both soluble, extramitochondrial enzymes a predominantly diffuse distribution throughout the cytoplasm would be expected, and the lack of this in smear preparations suggests that damage to the membrane induced by the spreading technique may have allowed leakage and therefore loss of enzyme into the surrounding aqueous medium during incubation.

The technique also seems to be suitable for the demonstration of enzymes which have an intramitochondrial location. The addition of sodium succinate or $a$-glycerophosphate as substrate causes an appreciable increase in the amount of formazan production compared with 'control' preparations lacking substrate. This suggests that sufficient damage to the mitochondrial membrane occurs during incubation to allow entry of substrate to react with intramitochondrial succinate and $a$-glycerophosphate (NAD-independent) dehydrogenases.

For 'control' preparations cells were incubated in an otherwise appropriate incubation solution but lacking substrate. The amount of formazan deposited in individual cells in such so-called 'controls' varies with the technique used. With fixed marrow films the formazan deposit was usually restricted to 1 or 2 granules only, which are too few to give a satisfactory microdensitometer reading. The cell suspension technique showed a considerable increase in the amount of 'control' formazan deposited (see Fig. 3) and this presumably reflects enzymatic reaction with endogenous substrate within the cell. This explanation is suggested by the similarity of the initial velocity of the activity-time curves, in the presence and absence of added exogenous substrate, within the first 20 minutes of incubation, ie, before exogenous substrate takes the place of endogenous substrate in the cell. Moreover when the incubation was performed under hyperbaric nitrogen conditions ( 3 atmospheres absolute pressure) the amount of formazan deposited per cell was increased considerably if there was excess exogenous substrate in the incubation solution, but to a lesser extent in the 'control' preparations; this suggests that hyperbaric conditions increase substrate penetration into the cell. The very weak endogenous enzyme activity obtained in fixed smears suggests either an inhibitory effect by the fixative or loss of endogenous enzyme or substrate from the cell by diffusion through a damaged cytoplasmic membrane. Previous workers have attempted to remove this endogenous activity altogether in order to achieve negative 'control' slides by washing the cells in normal saline (Gough and Elves, 1967), but preliminary studies of the metabolic activity of normal and leukaemic bone marrow cells have indicated that an assessment of the resting or endogenous cell enzyme activity may be as important as the maximal exogenous activity achieved when an excess of substrate is presented to the cell; consequently both values should be estimated.

The advantages of this technique, namely, absence of enzyme inhibition by fixation; avoidance of damage to the cytoplasmic membrane so that neither intracellular enzyme nor substrate leaks out of the cell; and a more accurate and objective assessment of enzyme activity in individual cells may be applied to the study of many other enzyme systems in individual cells. The ease with which leukaemic blast cells are disrupted to form 'smudge' cells is also a disadvan- 
tage in autoradiographic as well as cytochemical studies, and the use of the collagen polypeptide together with the cyto-centrifuge, may be of value in isotope-labelling experiments. It is hoped that the technique will permit a more accurate and meaningful assessment of metabolic activity in individual leukaemic cells.

We are indebted to Professor R. M. Hardisty and his staff, Department of Haematology, The Hospital for Sick Children, Great Ormond Street, London, WC1, who provided bone marrow specimens; and to British Glues and Chemicals Ltd, London, SE1, and the Endeavour Chemical Co Ltd, Beach Road, Newhaven, who made available various types of collagen polypeptide. We gratefully acknowledge a grant from the United Birmingham Hospitals Endowment Research Fund for equipment and for a travelling research fellowship to one of us (J.S.).

\section{REFERENCES}

Chayen, J., and Denby, E. F. (1968). Biophysical Technique as Applied to Cell Biology. Methuen. London.

Deeley, E. M. (1955). J. sci. Instrum. 32, 263.

De Souza, E. J., and Kothare, S. N. (1959). J. Histochem. Cytochem., $7,77$.

Gough, J., and Elves, M. W. (1967). Acta haemat. (Basel), 37, 42. Hayhoe, F. G. J., Quaglino, D., and Doll, R. (1964). Spec. Rep. Ser. med. Res. Coun. (Lond.), 304.

Quaglino, D., and Hayhoe, F. G. J. (1960). Nature (Lond.), 187, 85. Sacktor, B., and Dick, A. R. (1960). Cancer Res., 20, 1408.

Stuart, J., and Skowron, P. N. (1968). Brit. J. Haemat., 15, 443. 